\title{
Artigos
}

Emerson de Lima Pinto ${ }^{1}$

Mariana Kovara Jung ${ }^{2}$

\section{INTERPRETAÇÃO CONSTITUCIONAL: A GARANTIA DA SUPREMACIA DA CONSTITUIÇÃO}

\author{
CONSTITUTIONAL INTERPRETATION: \\ THE GUARANTEE OF CONSTITUTION SUPREMACY
}

\begin{abstract}
RESUMO:
É da essência do Direito a criação de mecanismos que permitam e facilitem a convivência em sociedade. A Constituição foi elaborada por meio da análise social, evidenciando a necessidade do estabelecimento de limites para que os indivíduos se respeitassem entre si. Neste trabalho, pretende-se abordar os elementos que garantem a supremacia do texto constitucional frente às demais normatizações pertencentes ao ordenamento jurídico. A interpretação é descrita como uma relevante parte do Direito, que se destina ao entendimento dos textos normativos
\end{abstract}

Palavras-chave: Direito; Ordenamento jurídico; Constituição; Interpretação constitucional; Princípios garantidores; Supremacia

\section{ABSTRACT:}

It is of the essence of the Law the creation of mechanisms that allow and facilitate the coexistence in society. The Constitution was drafted through social analysis, highlighting the need to set boundaries for individuals to respect each other. This paper intends to address the elements that guarantee the supremacy of the constitutional text over the other norms that belong to the legal system. Interpretation is described as a relevant part of law, in which it is intended for the understanding of normative texts.

Keywords: Law; Legal system; Constitution; Constitutional interpretation; Guaranteeing principles; Supremacy..

\section{A CIÊNCIA DO DIREITO}

Preliminarmente, busca-se conceituar, mesmo que sucintamente, a amplitude que a palavra Direito possui. Largamente, posto de maneira coloquial, a ideia de Direito subentende fazer algo de forma correta, aquilo que diverge do "errado" ou se remetermos à justiça, Direito é o justo, é o regramento que influencia os indivíduos a agirem de modo sociável, impondo certos limites para que um não afete a vida do outro. Comumente, "Direito é lei e ordem, isto é, um conjunto de regras obrigatórias que garante a convivência social graças ao estabelecimento de limites à ação de cada um dos seus membros. [...], quem age em conformidade com essas regras comporta-se direito; quem não o faz, age torto" (REALE, 2002, p. 1).

Consoante a Miguel Reale, Direito pode ser conceituado como direção, ligação e obrigatoriedade de um comportamento, consequentemente, é um fato ou fenômeno social, pois advém da sociedade e não existe fora dela. Destarte, o Direito se apresenta "sob múltiplas formas, em função de múltiplos campos de interesse, o que se reflete em distintas e renovadas estruturas normativas" (REALE, 2002, p. 2-3).

\footnotetext{
${ }^{1}$ Professor e pesquisador no Curso de Graduação em Direito na Universidade FEEVALE e CESUCA. ersonlp@terra.com.br (iD) https://orcid.org/0000-0002-8514-5801

${ }^{2}$ Acadêmica do curso de Direito do CESUCA Faculdade. mariana.kovara@gmail.com
} 
A pré-compreensão de Direito se firma em duas vertentes de estudos, sendo elas a Filosofia do Direito e a Ciência do Direito. Tais vertentes têm sua importância no meio em que o Direito se desenvolveu. De acordo com Reale (2002, p. 2-7), o Direito é uma estrutura de experiência social, em que diversos elementos foram examinados e organizados com a finalidade de conduzir os comportamentos sociais.

A Filosofia do Direito corresponde à investigação "permanente das condições morais, lógicas e históricas do fenômeno jurídico e da Ciência do Direito" (REALE, 2002, p. 14). Já a Ciência do Direito refere-se ao estudo do fenômeno jurídico social e sua concretização no espaço-tempo. A Ciência sempre trata do Direito Positivo, ou seja, o Direito que entrou em vigor e possui ou possuiu, eficácia durante sua vigência (REALE, 2002, p. 16-17).

Conforme Venosa (2019, p. 8), "nada é tão simples e ao mesmo tempo tão complexo quanto definir Direito". Como ciência, o Direito abrange a compreensão das normas, tanto as impostas pelo Estado, quanto as normas impostas pela natureza do Homem, não se limitando a estudar somente as regras, mas analisar e estabelecer conceitos e princípios que busquem esclarecer os fenômenos sociais bem como os negócios jurídicos. Desse modo, vale dizer que o Direito, como ciência, é um conjunto de normatizações que regulam as condutas para fins de adequação social (VENOSA, 2019, p. 8-10).

Desta forma, Reale (2002, p. 17) sintetiza a diferença entre Filosofia e Direito, arguindo que "[...] A Ciência do Direito estuda o fenômeno jurídico tal como ele se concretiza no espaço e no tempo, enquanto a Filosofia do Direito indaga das condições mediante as quais essa concretização é possível".

\section{UMA ABORDAGEM SOBRE A REPRE- SENTAÇÃO CLÁSSICA DO DIREITO}

Como salientado, o Direito pode ser considerado como lei e ordem, um conjunto de regras obrigatórias que garantem a convivência social mediante imposição de limites estabelecidos de acordo com ações de cada um dos seus membros. A palavra lei, segundo sua etimologia, refere-se à ligação, liame, laço, relação, o que se completa com o sentido nuclear de jus, que transparece o sentido de jungir, unir, ordenar, coordenar (REALE, 2002, p. 1-2). Mais do que distinguir o justo do injusto; o correto do incorreto, o Direito não é uma criação abstrata ou estática, concretiza-se diretamente na sociedade, na compreensão do viver e conviver, aprontando o que é ético nas relações (VENOSA, 2019, p. 7-8).

O Direito deve ser compreendido como um aglomerado de ideais, baseado em regras, normas positivas, ações destinadas a proteger e coibir certas condutas sociais, uma disciplina social a ser seguida, um sistema de representações intelectuais construídas a partir de princípios sociais estabelecidos, de modo independente dos fenômenos sociológicos ou históricos, dentre outras possibilidades. Jean-Louis Bergel (2001, p. 6) assegura que a busca pela definição de Direito se dá mediante a análise de diversas teses sustentadas:

\begin{abstract}
O direito, em si, é então, provavelmente, ao mesmo tempo produto dos fatos e da vontade do homem, um fenômeno material e um conjunto de valores morais e sociais, um ideal e uma realidade, um fenômeno histórico e uma ordem normativa, um conjunto de atos de vontade e de atos de autoridade de liberdade e de coerção... São suas diversas expressões que são parciais e expressam mais ou menos, conforme sistemas jurídicos e conforme as matérias, ora a ordem social ou os valores morais, ora o individualismo ou o coletivismo, ora a autoridade, ou a liberdade [...]
\end{abstract}

Segundo Kelsen (1998, p. 5-6), é impossível conhecer a natureza do Direito se a atenção for dirigida a apenas uma regra isolada. Somente compreendendo claramente as relações que constituem a ordem jurídica é que a natureza do Direito poderá ser entendida plenamente.

O fato de o Direito ser uma ordem da conduta humana não significa que a ordem jurídica diga respeito apenas à conduta humana, que nada além da conduta humana faça parte do conteúdo de regras jurídicas. Uma regra que torna o assassinato um delito punível diz respeito a 
uma conduta humana que tem a morte de um ser humano como efeito. A morte em si, porém, não é uma conduta humana, mas um processo fisiológico. Toda regra jurídica obriga os seres humanos a observarem certa conduta sob certas circunstâncias. Essas circunstâncias não precisam ser atos da conduta humana; podem ser, por exemplo, o que chamamos de eventos naturais [...] os fatos que não são fatos da conduta humana tendem a fazer parte do conteúdo de uma regra jurídica. No entanto, eles podem sê-lo apenas na medida em que estejam relacionados com a conduta humana, como sua condição ou como seu efeito (KELSEN, 1998, p. 6).

O Direito, conforme Reale (2002, p. 18), corresponde à exigência essencial e indeclinável de uma convivência ordenada, pois nenhuma sociedade poderia subsistir sem o mínimo de ordem, de direção e solidariedade. É notável que, desde as formas mais rudimentares de vida social, já havia uma intenção de ordem jurídica, mesmo sem propor significados lógicos ou morais. Reale (2002, p. 18) assegura que foi somente num estágio mais maduro de civilização que as regras jurídicas adquiriram estrutura e valor próprios, independentemente das crenças religiosas ou normas costumeiras. Nesse momento histórico, a humanidade passou a considerar o Direito como algo merecedor de estudos autônomos. Esse marco assinalou um momento crucial e decisivo para a espécie humana.

Bergel (2001, p. 22) afirma que é frequente que as funções do Direito sejam deixadas de lado, apenas objetivando as eficácias imediatas das soluções. Todo ordenamento jurídico busca descobrir o sentido de sua existência por meio de valores sociais, e estes pregam, por exemplo, a justiça, a segurança jurídica, o progresso social, e outros ideais que representam características para se alcançar uma sociedade com possibilidades de crescimento da sua população (BERGEL, 2001, p. 8).

$O$ raciocínio jurídico não pode ser reduzido a uma mera dedução lógica de sentido, pois, na realidade, é um constante confronto analítico entre o valor de uma solução e a coerência que este determinado valor possui para o mundo jurídico. Ainda há de se ressaltar o que R. David (apud BER-
GEL, 2001, p. 22-23) anuncia que "nossa concepção do direito visa a combinar numa ideia de justiça considerações tiradas da moral e da equidade e considerações de utilidade social e de eficácia material $[. .]$.$" . A partir desta consideração, pode se$ dizer que o Direito serve como uma espécie de balança, com a proposta de ponderar aquilo que diz respeito ao vivido e qual o resultado que sua conduta pode trazer à sociedade.

A utilidade do Direito corresponde à máxima de alcançar a satisfação do maior número de pessoas possível, buscando evitar dor e sofrimento (BERGEL, 2001, p. 23). Para que tal máxima seja atingida, o Direito consiste em avaliar critérios qualitativos das ações sobre as consequências para a vida social ou individual. Miguel Reale (2002, p. 62) menciona, em sua obra, que o Direito é um sistema de normas ou regras jurídicas que expressam comportamentos, expondo aos homens formas e possibilidades de agir.

O Direito, de acordo com Ferraz Junior (2018, p. 7), é concebido como uma ciência que protege o homem do poder arbitrário dos seus detentores. É um fator que postula a estabilidade social, compilando ideais que, algumas vezes, ditam não-ações, que são regramentos que condenam aqueles que praticam condutas opostas a convivência social. Diante das possíveis funções do Direito, é possível salientar que a criação de um ordenamento jurídico se torna a principal delas, pois, basicamente, o ordenamento jurídico é um sistema de normas (KELSEN, 1998, p. 161). Reale (2002, p. 190-192) explana que o ordenamento jurídico é um "sistema de normas", atualizado conforme as mudanças da sociedade, que não pode apresentar lacunas e deve ser "vigente e eficaz". Isso quer dizer que o ordenamento jurídico é a regulamentação social, que, por meio das fontes do Direito e de seu próprio conteúdo, constitui normas jurídicas com a finalidade de preencher as faIhas e dar limites ao poder discricionário.

De acordo com Kelsen (1998, p. 21), a "sociedade nada mais é que uma ordem social", visto que é mediante a sociedade que são impostos os comportamentos permitidos e quais medidas de coerção caso seja violada alguma proibição. 
Desse modo, pode-se dizer que o Direito é uma ordem coercitiva (REALE, 2002, p. 27). Dito, então, que uma comunidade social é uma ordem social, e que esta delimita a atuação dos indivíduos por meio de regras, vê-se aí o surgimento do ordenamento jurídico.

Kelsen (1998, p. 31) aduz que o Direito "assegura uma paz relativa, [...] na medida em que priva os indivíduos do direito de empregar a força, mas reserva-o à comunidade". Diz ainda que a paz do Direito não é estabelecida mediante a ausência da força, mas, sim, pelo seu direcionamento a um centralizador que monopolize a força da comunidade.

O Direito, com certeza, é uma ordenação que tem como fim a promoção da paz, na medida em que proíbe o uso da força nas relações entre os membros da comunidade. Contudo ele não exclui absolutamente o uso da força. 0 Direito e a força não devem ser compreendidos como absolutamente antagônicos. O Direito é organização da força. Porque o Direito vincula certas condições para o uso da força nas relações entre os homens, autorizando o emprego da força apenas por certos indivíduos e sob certas circunstancias. O Direito autoriza certa conduta que, sob todas as outras circunstâncias, deve ser considerada "proibida"; ser considerada proibida significa ser a própria condição para que tal ato coercitivo atue como sanção. $O$ indivíduo que, autorizado pela ordem jurídica, aplica a medida coercitiva (a sanção) atua como um agente dessa ordem ou - o que equivale dizer o mesmo - como um órgão da comunidade constituído por ela. Apenas esse indivíduo, apenas o órgão da comunidade, está autorizado a empregar a força. Por conseguinte, pode-se dizer que o Direito faz o uso da força um monopólio da comunidade. $E$, precisamente por fazê-lo, o Direito pacifica a comunidade (KELSEN, 1998, p. 30).

Destarte, Kelsen (1998, p. 40) e Venosa $(2019$, p. 86) asseguram que ordenamento jurídico é o Direito positivo, ou seja, o ordenamento são as normas jurídicas legislativas, judiciais, consuetudinárias e convencionais. Bergel (2001, p. 15) esclarece que o positivismo jurídico é o reconhecimento do valor das regras vigentes no Estado.

Assim, diante de tais alegações, é possível afirmar que a paz do Direito só é eficaz quando os indivíduos seguem a ordem jurídica estabelecida, respeitando os interesses comuns a todos, como vida, saúde, segurança, liberdade, propriedade. Destarte, o Direito é um ordenamento que regulamenta a conduta humana, atribuindo a cada um sua posição na comunidade e seus deveres. Portanto, aquele que não cumprir o seu dever, será punido por meio da técnica, do ato de coerção, por meio de uma sanção.

\section{A CONSTITUIÇÃO}

O primeiro Estado Moderno é absolutista, fruto do rompimento e fragmentação da forma estatal medieval. Streck $(2018$, p. 1) afirma que o absolutismo gerou condições para o surgimento de formas para controlar o poder, por meio de mecanismos para delimitar os poderes do príncipe. Nesse contexto, as limitações ocorreram na Inglaterra, no decorrer do século XVII, na França, no fim do século XVIII e com a Declaração de Independência das colônias americanas, que motivaram a Constituição de 1787.

Diante desse limitar de atos, o movimento constitucionalizador se deu por diferentes formas e em diversos Estados, agarrando-se em cada motivação histórica. Nas palavras de Streck (2018, p. 1), o autor esclarece o que é constitucionalismo:

[...] O constitucionalismo, pelas suas características contratualistas, vai se firmar como uma teoria que tem a Constituição como lei fundamental apta a limitar o poder, porém, mais do que isso, limitar o poder em benefício de direitos, os quais, conforme a evolução histórica, vão se construindo no engate das lutas políticas (direitos de primeira, segunda, terceira e quarta dimensões, que demonstram as diversas fases pelas quais passou o Estado de Direito a partir da revolução francesa até os dias atuais). O constitucionalismo é, assim, um movimento que objetiva colocar limites no político. E essa limitação assume diferentes matizes, chegando ao seu ápice no segundo pós-guerra, a partir da noção de Constituição dirigente e compromissória e da noção de Estado Democrático de Direito. 
De um modo geral, entende-se Constituição:

[...] como sistema de normas jurídicas, produzidas no exercício do poder constituinte, dirigidas precipuamente ao estabelecimento da forma de Estado, da forma de governo, do modo de aquisição e exercício do poder, da instituição e organização de seus órgãos, dos limites de sua atuação, dos direitos fundamentais e respectivas garantias e remédios constitucionais e da ordem econômica e social (MORAES, 2019, p. 78).

Hesse (2009) argumenta que as funções da Constituição são aplicáveis à vida em comunidade, principalmente no que se refere às tarefas fundamentais de formação e manutenção da unidade política e a criação e manutenção do ordenamento jurídico.

Esta Constituição determina primeiro as decisões que levam à unidade política, segundo as quais esta se deve executar e se devem levar a cabo as tarefas estatais. Tais decisões são, segundo a Lei Fundamental, a inviolabilidade da dignidade humana como princípio supremo do ordenamento constitucional, a república, a democracia, o postulado do Estado social de Direito, e a organização territorial em termos de Estado federal. Nas concreções posteriores de tais decisões, a Constituição ordena a organização e o procedimento de formação da unidade política e da ação estatal; estabelece limites à ação dos poderes públicos. Positiva normas segundo as quais se hão de constituir os órgãos do Estado, se há de determinar a orientação política global e se hão de decidir as questões pendentes. É essa mesma Constituição que regula as competências desses órgãos e, a grandes traços, o procedimento com que elas se hão de exercitar. E é ela também que estabelece o procedimento com que se hão de superar os conflitos que surjam dentro da comunidade (HESSE, 2009, p. 7).

Sobre a Constituição Federal Brasileira, Gilmar Mendes (2014, p. 55) declara que seu conceito versa sobre a justificativa da necessidade de uma doutrina jurídica específica para uma realidade constitucional da sociedade. A Constituição é a soma de fatores reais que coexistem, incluindo os interesses e as condições que permeiam a vida dos indivíduos. Dessa forma, ela nasce como um sistema assegurador de liberdades e direitos fundamentais e de institucionalização da separação de poderes, organizada por normas que formulam compromissos e apresentam necessidades sociais que o Estado deve observar (MENDES, 2014, p. 55).

Streck (2017, p. 111) conceitua que "a Constituição nasce como um paradoxo, porque, do mesmo modo que surge como exigência para conter o poder absoluto do rei, transforma-se em um indispensável mecanismo de contenção do poder das maiorias". Nessa perspectiva, tem-se que a Constituição é tanto o ser, bem como o dever ser, ela significa mais do que apenas o texto transcrito. Conforme Hesse (1991, p. 15), a Constituição busca expressar ordem e conformação à realidade política e social.

A Constituição adquire força normativa na medida em que logra realizar essa pretensão de eficácia. Essa constatação leva a outra indagação, concernente às possibilidades e aos limites de sua realização no contexto amplo de interdependência no qual esta pretensão de eficácia encontra-se inserida (HESSE, 1991, p. 16). (grifos do autor)

Sarlet, Marinoni e Mitidiero (2018, p. 217) argumentam que assim como o Direito em geral, a Constituição também deve ser compreendida, pois o texto constitucional não é um texto autoevidente, de forma que "a interpretação das normas constitucionais situa-se no contexto mais amplo da interpretação das normas jurídicas", de modo a observar suas peculiaridades ou métodos e princípios diferenciados de interpretação.

Muito embora se deva refutar uma autonomia da interpretação constitucional, até mesmo por exigência da unidade do sistema jurídico, integrado pelas normas constitucionais, também é verdade que a posição ocupada pela constituição na ordem jurídica, no plano da hierarquia das fontes do direito, por si só já indica que a interpretação constitucional implica uma atenção especial (SARLET; MARINONI; MITIDIERO, 2018, p. 217). 
Nesse sentido, a interpretação constitucional se transforma numa orientação para aplicar aos problemas jurídico-constitucionais, solucionando-os. Pode-se dizer, assim, que a interpretação constitucional é um processo no qual assume relevância de todo conteúdo dos textos normativos e dos elementos e circunstâncias do caso concreto que se busca resolver. Dessa forma, a interpretação abrange para sua análise todos os recursos do ser e do dever-ser que o envolvem (SARLET; MARINONI; MITIDIERO, 2018, p. 219).

Konrad Hesse (2009, p. 102-103) argumenta que a interpretação constitucional é necessária sempre que uma questão constitucional não permite que a resposta seja conclusiva. $O$ autor ainda expõe que a interpretação é fundamental devido à amplitude do texto constitucional, de forma que os problemas de interpretação são mais frequentes do que se comparados aos outros setores do ordenamento jurídico. Barroso (2009, p. 108-109) complementa o pensamento de Hesse, quando menciona que a interpretação constitucional segue princípios próprios e apresenta especificidades e complexidades que são inerentes ao âmbito constitucional, porém, cumpre salientar que, apesar da grandiosidade da interpretação constitucional, a interpretação geral do Direito partilha da mesma natureza e característica para análise. Ademais, cita Barroso (2009), há uma conexão arraigada entre a interpretação constitucional e a interpretação geral das leis, pois a primeira se concretiza, em grande parte, na verificação de compatibilidade da segunda, determinando se a lei ordinária em questão é compatível com as normas estabelecidas pela Constituição.

[...] Importância que aumenta, se isso for possível, numa ordem constitucional dotada de uma jurisdição constitucional de amplas proporções, como é a da Lei Fundamental. Se em virtude da própria Constituição o Tribunal Constitucional a interpreta com eficácia vinculante não só para o cidadão, mas também para os órgãos do Estado, a ideia que origina e legitima essa vinculação - que não é senão a de submissão de todo o poder do Estado à Constituição - só poderá tornar-se realidade se as sentenças do Tribunal expressarem o conteúdo da Constituição, ainda que na visão do Tribunal. Embora o Tribunal seja competente para fixar esse conteúdo com eficácia vinculante, nem por isso ele está acima da Constituição, à qual deve sua existência. Por isso, é fundamental para o cumprimento do objetivo do Tribunal, assim como para o processo constitucional como um todo, o modo como se resolva o problema da interpretação constitucional (HESSE, 2009, p. 102-103). (grifos do autor)

Tem-se que o objetivo da interpretação é chegar no resultado "constitucionalmente 'correto' através de um procedimento racional e controlável, fundamentando esse resultado de modo igualmente racional e controlável, e criando, dessa forma, certeza e previsibilidade jurídicas, ao invés de acaso, de simples decisão por decisão" (HESSE, 2009, p. 103). Dessa maneira, Hesse transmite que a interpretação busca a essência do problema, investigando o contexto da situação, aplicando métodos que permitam a elucidação do caso.

Nesta conjuntura, Barroso (2009, p. 107) leciona que a interpretação constitucional é composta pela hermenêutica jurídica, a interpretação, a aplicação e a construção. Tal afirmação, explica cada uma das questões:

A hermenêutica jurídica é um domínio teórico, especulativo, cujo objeto é a formulação, o estudo e a sistematização dos princípios e regras de interpretação do direito. A interpretação é atividade prática de revelar o conteúdo o significado e o alcance de uma norma, tendo por finalidade fazê-la incidir em um caso concreto. A aplicação de uma norma jurídica é o momento final do processo interpretativo, sua concretização pela efetiva incidência do preceito sobre a realidade de fato. Esses três conceitos são marcos no itinerário intelectivo que leva à realização do direito. Cuidam eles de apurar o conteúdo da norma, fazer a subsunção dos fatos e produzir a regra final, concreta, que regerá a espécie. [...] a construção significa tirar conclusões a respeito de matérias que estão fora e além das expressões contidas no texto e dos fatores nele considerados. São conclusões que se colhem no espírito, embora não na letra da norma. [...] a construção vai além e pode recorrer a considerações extrínsecas (BARROSO, 2009, p. 107-108). (grifos do autor) 
Acrescenta-se, assim, o ensinamento de Palmer (1969, p. 19-20), que argumenta que a "hermenêutica é o estudo da compreensão, é essencialmente a tarefa de compreender textos". O autor explica que o campo hermenêutico se originou do esforço para descrever situações históricas e humanísticas. Ainda segundo Palmer (1969, p. 19 -20), pode-se alegar que a teoria hermenêutica "é uma concepção da própria interpretação", de modo que todas as ações humanas são passíveis de compreensão, e os resultados são obtidos mediante processos de esclarecimento.

\section{A INTERPRETAÇÃO CONSTITUCIONAL}

Diante dos ensinamentos abordados, é vista a necessidade de os textos serem interpretados para que façam sentido e projetem seu valor. Nessa máxima, para que a Constituição de um país dite os direitos e deveres inerentes aos cidadãos, é imperioso que ela seja compreendida. Sarlet, Marinoni e Mitidiero (2018, p. 217) salientam que:

[...] a interpretação das normas constitucionais situa-se no contexto mais amplo da interpretação das normas jurídicas, de modo que desde logo se coloca a indagação a respeito da existência de peculiaridades da interpretação constitucional ou mesmo dos métodos e princípios diferenciados de interpretação. Muito embora se deva refutar uma autonomia da interpretação constitucional, até mesmo por exigência da unidade do sistema jurídico, integrado pelas normas constitucionais, também é verdade que a posição ocupada pela constituição na ordem jurídica, no plano da hierarquia das fontes do direito, por si só já indica que a interpretação constitucional implica uma atenção especial.

Sarlet, Marinoni e Mitidiero (2018, p. 219) destacam, em sua obra, que a interpretação constitucional se revela como uma orientação para a solução de problemas jurídico-constitucionais, e, dessa maneira, a interpretação constitucional seria a própria aplicação da Constituição. Nesse sentido, Häberle (1997, p. 13) completa o pensamento, abordando que "no processo de interpretação constitucional estão potencialmente vinculados todos os órgãos estatais, todas as potências públicas, todos os cidadãos e grupos"' concepção que mostra que todos integrantes da nação estão envolvidos nas interpretações constitucionais.

Härbele (1997, p. 24) ressalta que "até pouco tempo imperava a ideia de que o processo de interpretação constitucional estava reduzido aos órgãos estatais ou aos participantes diretos do processo"'Entretanto, tal pensamento foi dizimado, alegando-se que:

[...] A interpretação constitucional é, todavia, uma 'atividade' que, potencialmente, diz respeito a todos. Os grupos mencionados e o próprio indivíduo podem ser considerados intérpretes constitucionais indiretos ou a longo prazo. A conformação da realidade da Constituição torna-se também parte da interpretação das normas constitucionais pertinentes a essa realidade (HÄBERLE, 1997, p. 24).

Conforme o exposto, Barroso (2009, p. 110) cita que o texto das normas constitucionais deve ser interpretado sob a ótica de suas peculiaridades, pois:

O objeto da interpretação constitucional é a determinação dos significados das normas que integram a Constituição [...] Essa interpretação pode assumir duas modalidades: a) a da aplicação direta da norma constitucional, para reger uma situação jurídica [...] b) ou a de operação de controle de constitucionalidade, em que se verifica a compatibilidade de uma norma infraconstitucional com a Constituição.

Salienta, Garcia (2015, p. 513), que o método é o indicativo de um percurso para se alcançar um fim e, para tanto, admite-se o uso de "programas, processos ou técnicas passíveis de serem utilizados para que um dado objetivo seja atingido". Desse modo, o método é caracterizado por assumir características instrumentais, que resultam na interpretação.

Nesta ótica, Garcia (2015, p. 516) destaca que "os métodos de interpretação somente cumprem a sua funcionalidade quando atuam como verdadeiros fatores de conexão entre significantes 
e significado". Dito isso, passaremos a analisar os métodos de interpretação, que são: o método clássico; o método tópico problemático, o método científico-axiológico e o método concretizador (GARCIA, 2015, p. 516).

O método clássico de interpretação é aquele aplicável a todos os ramos do Direito, que se utiliza dos elementos clássicos - interpretação gramatical, histórica, sistemática e teleológica - para atingir seus resultados (BARROSO, 2009, p. 129). Barroso (2009, p. 129) expõe que a interpretação conforme os elementos clássicos "se faz a partir da norma (interpretação gramatical), de sua conexão (interpretação sistemática), de sua finalidade (interpretação teleológica) e de seu processo de criação (interpretação histórica)". O autor aduz que a interpretação gramatical é "o momento inicial do processo interpretativo", pois, é conforme o texto de lei que o intérprete deve ater sua atenção, devendo programar sua linha de raciocínio para a interpretação literal (BARROSO, 2009, p. 129; 131). Importa destacar que, apesar de ser "sempre o primeiro método a ser empregado na busca do verdadeiro significado da norma jurídica", ele não pode ser considerado como único ou como o mais relevante (FRIEDE, 2015, p. 164).

O elemento histórico "consiste na busca de sentido da lei através dos precedentes legislativos, dos trabalhos preparatórios" (BARROSO, 2009, p. 136). Barroso (2009, p. 137-139) argumenta que a interpretação histórica possui maior destaque na interpretação constitucional do que nas interpretações de textos ordinários, pois é imperioso o estudo dos movimentos sociais que antecederam os tempos atuais para se entender como chegamos ao momento atual.

A interpretação histórica também se traduz em outro meio importante de conhecer a lei e seu verdadeiro significado. Este método de interpretação consiste basicamente em considerar o conhecimento evolutivo (e, portanto, histórico) da linguagem utilizada na redação do texto legal para se chegar à essência do dispositivo normativo, buscando o verdadeiro significado da lei, eventualmente camuflado nas expressões antigas presentes no texto legal (FRIEDE, 2015, p. 137)
Os elementos sistemático e teleológico disputam "a primazia no processo interpretativo" (BARROSO, 2009, p. 140). A interpretação sistemática permite que o intérprete determine qual o dispositivo que deverá ser interpretado, realocando-o dentro de um contexto normativo, estabelecendo conexões que permitam percepções sobre a norma jurídica (BARROSO, 2009, p. 140-142).

\begin{abstract}
As leis, em sua grande maioria, encontram-se organizadas e, até mesmo, codificadas. Seus dispositivos em artigos, por exemplo, estão sempre abaixo de capítulos, títulos, livros etc., indicando, de qualquer forma, o assunto e, por efeito, o direito tutelado. A interpretação sistemática consiste, assim, no propósito de resolver eventuais conflitos de normas jurídicas, examinando-a sob a ótica de sua localização junto ao direito que tutela (FRIEDE, 2015, p. 166).
\end{abstract}

O elemento teleológico define que as normas devem atender ao seu espírito e à sua finalidade, o método teleológico "procura revelar o fim da norma, o valor ou bem jurídico visado pelo ordenamento com a edição de dado preceito" (BARROSO, 2009, p. 143). Assim, não há como discutir sobre a primazia de tais elementos, pois ambos devem estar juntos, pois cada um possui uma função diferente e essencial para a interpretação.

O método tópico-problemático é relacionado "à superação de certas incongruências quanto ao modo de ver o sistema jurídico e à funcionalidade da atividade desenvolvida pelo intérprete" (GARCIA, 2015, p. 525). Conforme Garcia (2015, p. 525-526), o pensamento problemático ou tópico, surgiu da necessidade de reconhecer e delinear o problema da norma, realçando "o papel desempenhado pelo intérprete", justificando, assim, que, para a utilização dessa metodologia, a identificação do problema e a busca de oportunidades são as melhores possibilidades para se atingir a resolução. Dessa forma, o intérprete deve apontar todas as problemáticas relevantes encontradas ao longo de sua interpretação e apontar premissas que possam saná-la.

O método científico-axiológico "busca relacionar a ordem de valores subjacente à Constitui- 
ção formal com a sua função de integração da coletividade, o que exige a identificação da realidade que concretiza esta última, com seus valores e aspirações" GARCIA, 2015, p. 516). Por fim, o método concretizador estabelece que o intérprete deve individualizar o problema concreto que pretende superar. Garcia (2015, p. 537) afirma que é possível que os elementos estruturais do método concretizador - "(a) a importância atribuída ao problema, (b) a necessária relação entre programa e âmbito da norma e (c) a adstrição do intérprete aos balizamentos oferecidos pelo texto" - sejam usados durante a utilização do método axiológico da interpretação constitucional.

Consoante os métodos abordados, Barroso $(2009$, p. 128) afirma que é notável que "a interpretação constitucional é um fenômeno múltiplo", que sofre diversas influências para sua apreciação. Ainda neste campo, é imperioso destacar a presença dos princípios inerentes à interpretação constitucional, pois são eles as "normas eleitas pelo constituinte como fundamentos ou qualificações essenciais da ordem jurídica" (BARROSO, 2009, p. 155).

\section{OS PRINCÍPIOS GARANTIDORES DA SUPREMACIA DA CONSTITUIÇÃO}

De acordo com Sarlet, Marinoni e Mitidiero (2018, p. 222), os princípios da interpretação constitucional designam técnicas e diretrizes para assegurar uma metodologia racional e controlável ao processo de interpretação e aplicação das normas da Constituição.

Um típico operador jurídico formado na tradição romano-germânica, como é o caso brasileiro, diante de um problema que lhe caiba resolver, adotará uma linha de raciocínio semelhante à que se descreve a seguir. Após examinar a situação de fato que lhe foi trazida, irá identificar no ordenamento positivo a norma que deverá reger aquela hipótese. Em seguida, procederá a um tipo de raciocínio lógico, de natureza silogística, no qual a norma será a premissa maior, os fatos serão a premissa menor e a conclusão será a consequência do enquadramento dos fatos à norma (BARROSO, 2018, p. 93).
Nesse contexto, Barroso (2018) salienta que o emprego dos princípios de interpretação constitucional está voltado diretamente ao intérprete, e não propriamente ao conteúdo ou estrutura. Os princípios devem ser entendidos como "premissas conceituais, metodológicas ou finalísticas que devem anteceder, no processo intelectual do intérprete, a solução concreta da questão posta" (BARROSO, 2018, p. 93). Dito isso, o autor dispõe que são seis princípios que permeiam a interpretação constitucional, sendo eles: unidade da Constituição, supremacia da Constituição, interpretação conforme a Constituição, presunção de constitucionalidade das leis e atos, razoabilidade ou proporcionalidade e efetividade.

O princípio da unidade da Constituição, exposto por Sarlet, Marinoni e Mitidiero (2018, p. 222), "implica no âmbito da interpretação constitucional cada norma constitucional deve ser interpretada e aplicada de modo a considerar a circunstância de que a Constituição representa uma unidade, um todo indivisível".

\begin{abstract}
O problema maior associado ao princípio da unidade não diz respeito aos conflitos que surgem entre as normas infraconstitucionais ou entre estas e a Constituição, mas sim às tensões que se estabelecem dentro da própria Constituição. De fato, a Constituição é um documento dialético, fruto do debate e da composição política. Como consequência, abriga no seu corpo valores e interesses contrapostos. Nesses casos, como intuitivo, a solução das colisões entre normas não pode se beneficiar, de maneira significativa, dos critérios tradicionais (BARROSO, 2018, p. 93).
\end{abstract}

Barroso (2018, p. 93) conceitua esse princípio como uma interpretação sistemática, pois estabelece ao intérprete "o dever de harmonizar as tensões e contradições entre normas jurídicas", e em algumas situações deverá ponderar entre os bens jurídicos tutelados, preservando a essência de cada um.

A supremacia da Constituição é um princípio que distingue o poder hierárquico a toda e qualquer norma oriunda do texto constitucional. 
De acordo com Sarlet, Marinoni e Mitidiero (2018, p. 228), o princípio da supremacia da Constituição situa-se "no topo da hierarquia do sistema normativo", uma vez que é por meio da Constituição que os direitos fundamentais estão consagrados.

\begin{abstract}
Com a promulgação da Constituição, a soberania popular se converte em supremacia constitucional. Do ponto de vista jurídico, este é o principal traço distintivo da Constituição: sua posição hierárquica superior às demais normas do sistema. A Constituição é dotada de supremacia e prevalece sobre o processo político majoritário - isto é, sobre a vontade do poder constituído e sobre as leis em geral - porque fruto de uma manifestação especial da vontade popular, em uma conjuntura própria, em um momento constitucional" (BARROSO, 2018, p. 92). (grifos do autor)
\end{abstract}

Nessa lógica, Barroso (2018) leciona que, para que seja assegurada a supremacia do texto constitucional, o ordenamento jurídico concebeu mecanismos para análise da eficácia de atos que, de certo modo, tenham contradições à Constituição, conhecidos como controle de constitucionalidade.

No Brasil, esse controle é desempenhado por
meio de dois ritos diversos: (i) a via incidental,
pela qual a inconstitucionalidade de uma nor-
ma pode ser suscitada em qualquer processo
judicial, perante qualquer juízo ou tribunal,
cabendo ao órgão judicial deixar de aplicar a
norma indigitada ao caso concreto, se conside-
rar fundada a arguição; e (ii) a via principal,
pela qual algumas pessoas, órgãos ou entida-
des, constantes do art. 103 da Constituição
Federal podem propor uma ação direta peran-
te o Supremo Tribunal Federal, na qual se dis-
cutirá a constitucionalidade ou inconstitucio-
nalidade, em tese, de determinada lei ou ato
normativo (BARROSO, 2018, p. 92).

A interpretação conforme a Constituição se destina às normas infraconstitucionais, obrigandoas a seguirem os precedentes normatizados no texto constitucional, a fim de preservar a validade dos bens jurídicos por ela tutelados. Esse princípio é associado ao mecanismo de controle de constitucionalidade, pois "permite que o intérprete, sobre- tudo o tribunal constitucional, preserve a validade de uma lei que, na sua leitura mais óbvia, seria inconstitucional" (BARROSO, 2018, p. 92).

Segundo Barroso (2018, p. 92), o princípio da presunção de constitucionalidade das leis e atos normativos dispõe que, para que haja validade dos atos praticados pelo Poder Público, devem ser realizados conforme os ditames da Constituição. Sobre o Poder Público, o autor argumenta: "sua atuação se funda na legitimidade democrática dos agentes públicos eleitos, no dever de promoção do interesse público e no respeito aos princípios constitucionais, inclusive e notadamente os que regem a Administração Pública (art. 37)" (BARROSO, 2018, p. 93).

[...] Em um Estado constitucional de direito, os três Poderes interpretam a Constituição. A presunção de constitucionalidade, portanto, é uma decorrência do princípio da separação de Poderes e funciona como fator de autolimitação da atuação judicial. Em razão disso, não devem juízes e tribunais, como regra, declarar a inconstitucionalidade de lei ou ato normativo quando: (i) a inconstitucionalidade não for patente e inequívoca, existindo tese jurídica razoável para preservação da norma; (ii) seja possível decidir a questão por outro fundamento, evitando-se a invalidação de ato de outro Poder; e (iii) existir interpretação alternativa possível, que permita afirmar a compatibilidade da norma com a Constituição (BARROSO, 2018, p. 93).

Embora não esteja expresso na Constituição, o princípio da razoabilidade ou da proporcionalidade fundamenta-se nos ideais constitucionais do devido processo legal e na própria justiça. Esse princípio é visto como uma proteção aos direitos fundamentais do indivíduo e do interesse público, permitindo que a discricionariedade dos atos do Poder Público seja controlada (BARROSO, 2018, p. 94).

Em resumo sumário, o princípio da razoabilidade permite ao Judiciário invalidar atos legislativos ou administrativos quando: (i) não haja adequação entre o fim perseguido e o instrumento empregado (adequação); (ii) a medida não seja exigível ou necessária, havendo meio alternativo menos gra- 
voso para chegar ao mesmo resultado (necessidade/vedação do excesso); (iii) os custos superem os benefícios, ou seja, o que se perde com a medida é de maior relevo do que aquilo que se ganha (proporcionalidade em sentido estrito). O princípio pode operar, também, no sentido de permitir que o juiz gradue o peso da norma, em uma determinada incidência, de modo a não permitir que ela produza um resultado indesejado pelo sistema, fazendo assim a justiça do caso concreto (BARROSO, 2018, p. 94). (grifos do autor)

O último princípio, o da efetividade, significa a realização do Direito. É "a aproximação tão íntima quanto possível, entre o dever-ser normativo e o ser da realidade social" (BARROSO, 2019, p. 94). Diante dessa concepção, Barroso (2018, p. 94) declara:

[...] O intérprete constitucional deve ter compromisso com a efetividade da Constituição: entre interpretações alternativas e plausíveis, deverá prestigiar aquela que permita a atuação da vontade constitucional, evitando, no limite do possível, soluções que se refugiem no argumento da não autoaplicabilidade da norma ou na ocorrência de omissão do legislador.

É visto que todos os princípios referentes à interpretação constitucional destinam-se ao mesmo objeto, que é a manutenção da supremacia do seu texto. Embora os princípios assemelhem-se em definições, é notável que cada um visa a abranger uma possível lacuna, dificultando o surgimento de brechas que prenunciem discórdias à Constituição tanto na presença de divergência em seu texto quanto no entendimento das normas infraconstitucionais.

\section{CONCLUSÃO}

Da necessidade de compreender o mundo que o cerca, o homem desenvolveu métodos que permitissem a descoberta do desconhecido. Dela, destaca-se a interpretação, que contribui para que o intérprete possa alcançar o conhecimento e transformá-lo em sabedoria.

A interpretação é descrita como uma relevante parte do Direito, na qual destina-se ao en- tendimento dos textos normativo. O texto normativo, sem a devida interpretação, nada mais é do que apenas um aglomerado de palavras dispostas em uma frase. Entretanto, quando passa pelo processo interpretativo, o texto é analisado conforme sua disposição gramatical, e, juntamente com a investigação do momento histórico em que foi elaborada e seus preceitos sistemáticos e teleológicos, o intérprete possui condições de apurar o sentido que o legislador tentou transmitir e captar o significado, transformando o texto em realmente normativo, pois possui a essência de emitir direito ou obrigação.

A interpretação constitucional tem o condão de ratificar o texto magno do país. Por meio de seus métodos e princípios de apreciação normativos, fica evidente que toda e qualquer legislação infraconstitucional deve ser lida e compreendida à luz da Constituição. Por meio da interpretação constitucional, os direitos fundamentais, individuais e coletivos são reassegurados e disseminados a todas as áreas do Direito.

\section{REFERÊNCIAS}

BARROSO, Luís Roberto. Interpretação constitucional como interpretação específica. In: CANOTILHO, J. J. Gomes. Comentários à Constituição do Brasil. 2. ed. São Paulo: Saraiva Educação, 2018. Disponível em: https://integrada.minhabiblioteca.com.br/ \#/books/9788553602377/. Acesso em: 15 ago. 2019.

BARROSO, Luís Roberto. Interpretação e aplicação da Constituição: fundamentos de uma dogmática constitucional transformadora. 7. ed. rev. São Paulo: Saraiva, 2009.

BERGEL, Jean-Louis. Teoria geral do direito. São Paulo: Martins Fontes, 2001.

FERRAZ JUNIOR, Tercio Sampaio. Introdução ao estudo do direito: técnica, decisão, dominação. 10. ed. rev., atual. e ampl. São Paulo: Atlas, 2018. Disponível em: https://integrada.minhabiblioteca. com.br/\#/books/9788597014051/. Acesso em: 15 
ago. 2019.

FRIEDE, Reis. Ciência do Direito, norma, interpretação e hermenêutica jurídica. 9. ed. Barueri, SP: Manole, 2015. E-book. Disponível em: https:// integrada.minhabiblioteca.com.br/\#/books/ 9788520446263/. Acesso em: 15 ago. 2019.

GARCIA, Emerson. Interpretação constitucional: a resolução das conflitualidades intrínsecas da norma constitucional. São Paulo: Atlas, 2015. Disponível em: https://integrada.minhabiblioteca.com.br/ \#/books/9788522499878/. Acesso em: 15 ago. 2019.

HÄBERLE, Peter. Hermenêutica constitucional. A sociedade aberta dos intérpretes da Constituição: contribuição para a intepretação pluralista e 'procedimental' da Constituição. Porto Alegre: S. A. Fabris, 1997.

HESSE, Konrad. A força normativa da Constituição. Porto Alegre: S. A. Fabris, 1991.

HESSE, Konrad. Temas fundamentais do direito constitucional. São Paulo: Saraiva, 2009. Disponível em: https://integrada.minhabiblioteca.com.br/ \#/books/9788502139480/. Acesso em: 15 ago. 2019.

KELSEN, Hans. Teoria geral do direito e do estado. 3. ed. São Paulo: Martins Fontes, 1998.

MENDES, Gilmar Ferreira. Curso de direito constitucional. 9. ed. rev. e atual. São Paulo: Saraiva, 2014.
MORAES, Guilherme Peña de. Curso de Direito Constitucional. 11. ed. São Paulo: Atlas, 2019. Disponível em: https://integrada.minhabiblioteca. com.br/\#/books/9788597015805/. Acesso em: 15 ago. 2019.

PALMER, Richard E. Hermenêutica. Lisboa: Edições 70, 1969.

REALE, Miguel. Lições preliminares de direito. 27. ed. São Paulo: Saraiva, 2002.

SARLET, Ingo Wolfgang; MARINONI, Luiz Guilherme; MITIDIERO, Daniel. Curso de direito constitucional. 7. ed. São Paulo: Saraiva Educação, 2018. Disponível em: https://integrada.minhabiblioteca. com.br/\#/books/9788553172719/. Acesso em: 15 ago. 2019.

STRECK, Lenio Luiz. Jurisdição Constitucional. 5. ed. Rio de Janeiro: Forense, 2018. Disponível em: https://integrada.minhabiblioteca.com.br/\#/ books/9788530979492/. Acesso em: 15 ago. 2019.

STRECK, Lenio Luiz. Verdade e consenso. 6. ed. rev. e ampl. São Paulo: Saraiva, 2017. Disponível em: https://integrada.minhabiblioteca.com.br/\#/ books/9788547215644/. Acesso em: 15 ago. 2019.

VENOSA, Sílvio Salvo. Introdução ao estudo do direito. 6. ed. São Paulo: Atlas, 2019. Disponível em: https://integrada.minhabiblioteca.com.br/\#/ books/9788597018592/. Acesso em: 15 ago. 2019. 